\title{
Mechanistic Organic Photochemistry
}

\author{
Jakob Wirz*
}

\begin{abstract}
The photochemistry group in Basel has focused on the identification and characterization of organic reactive intermediates by flash photolysis with optical and infrared detection. In recent years, these techniques have been applied predominantly to determine the release rates of commonly used photoremovable protecting groups.
\end{abstract}

Keywords: Biradicals · Flash photolysis · Keto-enol tautomerism · Photoremovable protecting groups

\section{Introduction}

Photochemistry is fun! When I started my thesis work on the photohydrolysis of trifluoromethylphenols and -naphthols ${ }^{[1]}$ with Edgar Heilbronner and Kurt Schaffner at the ETH Zürich in 1966, the general lines of thought on how to understand the reactivity of electronically excited molecules were just emerging. T. Förster, G. N. Lewis and M. Kasha, G. Porter, E. Havinga, R. Woodward and R. Hoffmann, G. Hammond, H. Zimmerman, J. Michl, and L. Salem were among the intellectual leaders who developed the basic concepts for structure-reactivity correlations in photochemistry.

These were exciting times for a young photochemist. Spectroscopic techniques together with computational methods began to provide adequate characterization of excited states and their electronic properties. Simple models such as correlation diagrams ventured into the qualitative prediction of

${ }^{*}$ Correspondence: Prof. Dr. J. Wirz

Departement Chemie der Universität Basel

Klingelbergerstrasse 80

$\mathrm{CH}-4056$ Basel

Tel.: +41612673842

E-Mail: J.Wirz@unibas.ch potential energy surfaces of excited singlet and triplet states. Matrix isolation at cryogenic temperatures permitted the unambiguous identification of reactive intermediates. Last but not least, the rapid development of commercially available lasers and electronic equipment allowed direct, real-time detection of primary transient intermediates by flash photolysis. Photochemistry thus emerged as a key tool to study organic reaction mechanisms in general, because it often allows the generation of the same reactive intermediates that are involved, but usually not detectable, in ground-state chemistry, and thereby to determine their reactivity in solution directly.

A remarkable amount of knowledge on transient intermediates had already been deduced from the conventional, welldesigned methods of mechanistic organic chemistry that employed standard laboratory techniques such as quenching and sensitization, trapping, or radical clocks. Working backwards from the stable photoproducts and the variation of their yield as a function of various additives requires demanding preparative and analytical efforts. Flash photolysis is often easier and provides absolute rate constants, but itself yields precious little hard information that allows the identification of the observed transients. Kinetic data obtained by optical flash photolysis are thus prone to false assignments. Once a hypothetical reaction mechanism has been put forth, a stringent test for the assignment of the transients observed by flash photolysis is provided by comparing quantitative product distributions and quantum yields with the effect of added reagents on the transient kinetics. Moreover, time-resolved spectroscopies conveying structural information such as IR, Raman or EPR and CIDNP can also provide unambiguous assignments.

\section{Biradicals}

Biradicals are frequently the primary photoproducts of photoreactions. Their chameleon-like electronic structure, owing to the near degeneracy of several electronic states, complicates an anticipation of their chemical properties, and their intrinsic instability has long discouraged attempts to exploit their synthetic potential as bifunctional reagents.

We have investigated numerous conjugated biradicals and biradicaloids. ${ }^{[2-7]}$ For localized 1,n-biradicals ( $>2$ ), the singlet-triplet energy gap is usually $\leq k \mathrm{~T}$ at room temperature. The mechanism shown in Scheme 1 for the reactions of 1,3-diphenylcyclopentane-1,3-diyl, [8] which has a triplet ground state, may be generalized to a blueprint for reactions proceeding via biradicals ${ }^{[3-7,9]}$ as well as carbenes ${ }^{[10]}$ and nitrenes.[11] Substituents strongly influence the singlet-triplet energy gap and intersystem crossing rates in predictable ways $^{[9]}$ (see also Fig.). 2,2-Difluoro- and 2,2-dimethoxy-substituted cyclopentane1,3-diyls have a singlet ground state. They exhibit strong absorption in the visible region (500-600 nm) and may persist up to microseconds in solution. ${ }^{[12]}$

\section{Proton Transfer Reactions: Kinetic Studies of Keto-Enol Equilibria}

The first direct determination of an acidity constant of a simple enol ${ }^{[13]}$ by flash photolytic titration led to a long-standing, most fruitful cooperation with J. Kresge in Toronto. ${ }^{[14]}$ Numerous kinetically unstable enols and ynols ${ }^{[15,16]}$ as well as keto tautomers of phenols ${ }^{[17]}$ were generated in higher than equilibrium concentrations by flash photolysis of appropriate precur- 


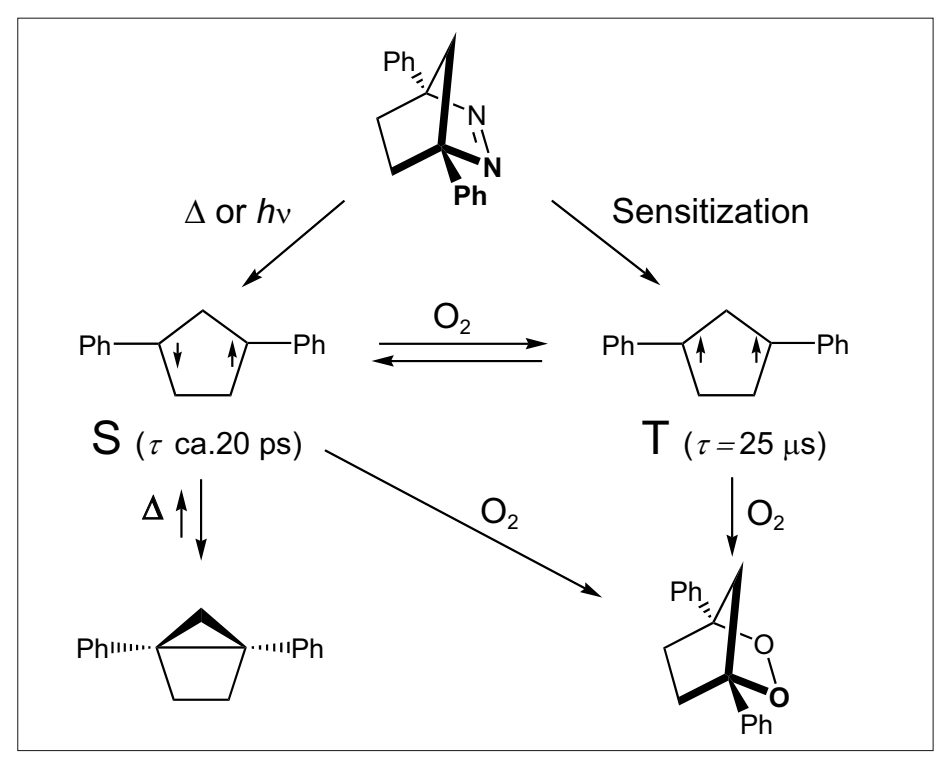

Scheme 1.

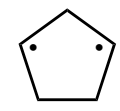

$260 \mathrm{~ns}$

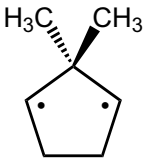

$<0.1 \mathrm{~ns}$

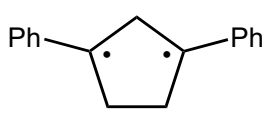

$16 \mu \mathrm{s}$

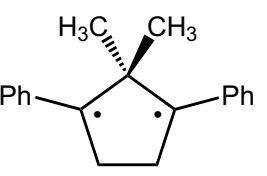

$1.2 \mu \mathrm{s}$

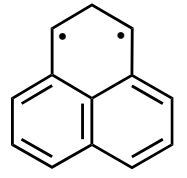

$>20 \mathrm{~ms}$

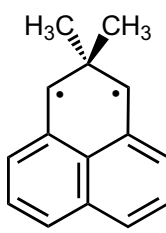

$400 \mu \mathrm{s}$
Table. Kinetic and thermodynamic parameters of keto-enol prototropism[18]

\begin{tabular}{|c|c|c|c|c|c|}
\hline $\begin{array}{l}\text { Carbonyl } \\
\text { compound }\end{array}$ & Enol & $\mathrm{p} K_{\mathrm{E}}$ & $p K_{a} \mathrm{E}$ & $\begin{array}{l}\log \left(k^{K} H_{H^{+}}\right. \\
\left./ M^{-1} s^{-1}\right)\end{array}$ & $\begin{array}{l}\log \left(k^{\prime} \mathrm{K}_{\mathrm{H}^{+}}\right. \\
\left./ \mathrm{M}^{-1} \mathrm{~s}^{-1}\right)\end{array}$ \\
\hline $\mathrm{Ph}-\mathrm{CH}=\mathrm{C}=\mathrm{O}$ & $\mathrm{Ph}-\mathrm{C} \equiv \mathrm{C}-\mathrm{OH}$ & $\approx 25$ & $\leq 2.8$ & - & 10.2 \\
\hline Mandelic acid & $\mathrm{Ph}-\mathrm{CHOHCH}\left((\mathrm{OH})_{2}\right.$ & 16.2 & 6.4 & 4.0 & 9.0 \\
\hline$\left(\mathrm{CH}_{3}\right)_{2} \mathrm{C}=\mathrm{O}$ & $\mathrm{CH}_{3} \mathrm{CHOHCH}_{3}$ & 8.3 & 10.9 & 3.7 & 9.8 \\
\hline $\mathrm{Ph}-\mathrm{CO}-\mathrm{CH}_{3}$ & $\mathrm{Ph}-\mathrm{CHOH}=\mathrm{CH}_{2}$ & 8.0 & 10.3 & 3.1 & 9.6 \\
\hline $\mathrm{CH}_{3} \mathrm{CH}=\mathrm{O}$ & $\mathrm{CH}_{2} \mathrm{CHOH}$ & 6.2 & 10.5 & 1.5 & 9.1 \\
\hline 9-Anthrone & 9-Anthrol & 2.2 & 7.8 & -1.4 & 5.1 \\
\hline Cyclohexa-2,4-dienone & $\mathrm{Ph}-\mathrm{OH}$ & -12.7 & 9.8 & -7.0 & 0.68 \\
\hline
\end{tabular}

a) The second-order rate constants $k^{\mathrm{K}}{ }_{\mathrm{H}_{+}}$and $k^{\mathrm{\prime}} \mathrm{K}_{\mathrm{H}_{+}}$refer to acid-catalyzed ketonization of the enol and enolate, respectively.<smiles>[R]C(=O)c1ccccc1[N+](=O)[O-]</smiles>

sors. ${ }^{[18]}$ Combination of the rate constants of ketonization and enolization provided accurate equilibrium constants of enolization, $K_{\mathrm{E}}=k^{\mathrm{E}} / k^{\mathrm{K}}$. Acidity constants of the corresponding ketones, $K_{\mathrm{a}}{ }^{\mathrm{K}}$, could then be calculated from a thermodynamic cycle, $\mathrm{p} K_{\mathrm{a}}^{\mathrm{K}}=\mathrm{p} K_{\mathrm{E}}+\mathrm{p} K_{\mathrm{a}}^{\mathrm{E}}$ (Table).

\section{Photoremovable Protecting Groups}

Photolabile protecting groups have seen a renaissance in recent years. They offer the means to deliver bioactive materials such as neurotransmitters, ATP or $\mathrm{Ca}^{2+}$ ions rapidly to small, addressable target sites and to follow the ensuing physiological events in real time. Amplified chemical effects may be achieved by light-controlled enzyme activity, gene expression or ion channel permeability using phototriggers or photoswitches. Recent developments include time-resolved X-ray crystallography, two-photon excitation by highly focused, ultrashort nearinfrared laser pulses, and kinetic studies on the early events in protein folding.

Nitrobenzyl derivatives are by far the most common photolabile protecting groups, and many nitrobenzyl-protected biochemicals are commercially available. For many years it had been assumed that the release of their substrates is, in general, synchronous with the decay of the primary aci-nitro intermediates that are readily observed at $400 \mathrm{~nm}$ by flash photolysis and exhibit lifetimes upwards of $0.1 \mathrm{~ms}$ in neutral aqueous solutions. In fact, the release occurs at the end of a complex sequence of reactions (Scheme 2), and the aci-nitro decay may be far from rate-determining, depending on $\mathrm{pH}$, buffer concentration, and on the nucleofugacity of the leaving group. ${ }^{[19]}$

Numerous photoremovable protecting groups initiated by the related photoenolization of $o$-alkylacetophenone derivatives have been developed in cooperation with the group of P. Klan, Brno, mainly for preparative purposes. ${ }^{[20]}$ The same principle is used in peri-alkyl substituted 1,4-naphthoquinone derivatives, which absorb strongly throughout the near UV region. [21]

Much faster release on a low nanosecond time scale is achieved with benzoin ${ }^{[22]}$ and dimethoxybenzoin protecting groups. ${ }^{[23]}$ Most promising are the $p$-hydroxyphenacyl phototriggers. The reaction proceeds with high quantum yields in aqueous media, predominantly from the lowest triplet state, and yields $p$-hydroxyphenylacetic acid as a physiologically benign, largely transparent side product (Favorskii rearrangement, Scheme 3).[24] Ongoing investigations provide evidence for reaction via a short-lived spirodione intermediate that decarbonylates at low water concentrations. 


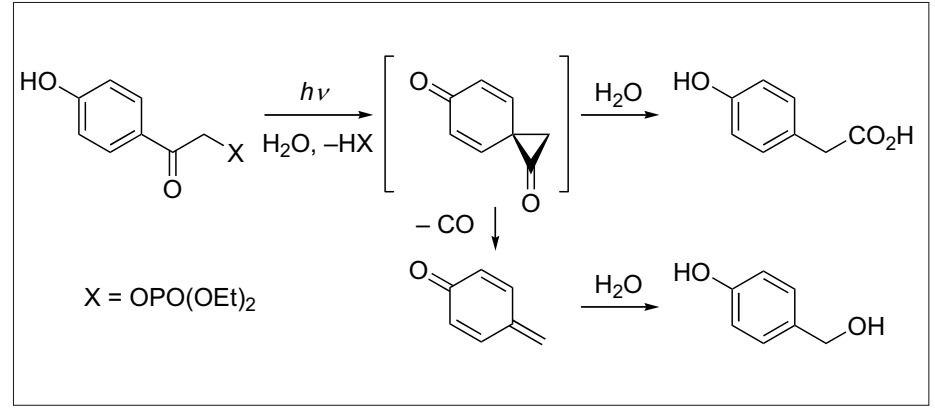

Scheme 3.

We are currently investigating photorelease from protecting groups with a xanthenyl chromophore, whose absorption extends up to $560 \mathrm{~nm} .{ }^{[25]}$

\section{Whither Photochemistry?}

Light adds a new dimension to chemistry. The interaction with other research groups has repeatedly led us into exciting new areas such as protein folding, ${ }^{[26]}$ abiotic photodegradation in surface waters, ${ }^{[27]}$ photoinitiators ${ }^{[28]}$ and photochromism, ${ }^{[29]}$ and the study of electron transfer in proteins ${ }^{[30]}$ or in a synthetic cytochrome P450 mimic. [31]

Photochemistry and photophysics have emerged from a relatively small community of specialists to become an integral part of and powerful tool for all branches of science: chemistry, biochemistry, biophysics, materials science, analytical chemistry, etc. Fluorescence measurements with spatial, temporal and spectral resolution are becoming available at decreasing cost along with continuously rising sensitivity and resolution, ultimately allowing the detection of single molecules and to follow their reactions and movements in space and time. To exploit this ever rising wealth of information, the expertise of well-trained professionals, who are acquainted with the arts and pitfalls of the trade, will stay in demand.

\section{Acknowledgments}

Throughout my career, I have been extremely fortunate to profit from the dedication of my often outstanding coworkers, from fruitful collaborations with colleague friends in many countries, from encouragement and support by my mentors, as well as from continuous funding by the Swiss National Science Foundation and occasional substantial donations by the chemical industry in Basel, notably Ciba Specialty Chemicals and its predecessor companies.

Received: July 27, 2007

[1] P. Seiler, J. Wirz, Helv. Chim. Acta 1972 , 55, 2693.

[2] W. Leupin, J. Wirz, J. Am. Chem. Soc. 1980, 102, 6068 .
[3] J. Wirz, Pure Appl. Chem. 1984, 56, 1289.

[4] M. Gisin, J. Wirz, Helv. Chim. Acta 1976, 59, 2273.

[5] M. Gisin, E. Rommel, J. Wirz, M. N. Burnett, R. M. Pagni, J. Am. Chem. Soc. 1979, 101, 2216; M. N. Burnett, R. Boothe, E. Clark, M. Gisin, H. M. Hassaneen, G. Persy, R. J. Smith, R. M. Pagni, J. Wirz, J. Am. Chem. Soc. 1988, 110, 2527.

[6] J. Ackermann, H. Angliker, E. Hasler, J. Wirz, Angew. Chem. 1982, 94, 632; Angew. Chem., Int. Ed. 1982, 21, 618; E. Hasler, A. Hörmann, G. Persy, H. Platsch, J. Wirz, J. Am. Chem. Soc. 1993, 115, 5400.

[7] D. R. McMasters, J. Wirz, G. J. Snyder, J. Am. Chem. Soc. 1997, 119, 8568. D. R. McMasters, J. Wirz, J. Am. Chem. Soc. 2001, 123, 238.

[8] W. Adam, S. Grabowski, H. Platsch, K. Hannemann, J. Wirz, R. M. Wilson, J. Am. Chem. Soc. 1989, 111, 751.

[9] F. Kita, W. Adam, P. Jordan, W. M. Nau, J. Wirz, J. Am. Chem. Soc. 1999, 121, 9265.

[10] M. C. Biewer, M. S. Platz, M. Roth, J. Wirz, J. Am. Chem. Soc. 1991, 113, 8069.

[11] E. Leyva, M. S. Platz, G. Persy, J. Wirz, J. Am. Chem. Soc. 1986, 108, 3783.

[12] W. Adam, W. T. Borden, C. Burda, H. Foster, T. Heidenfelder, M. Heubes, D. A. Hrovat, F. Kita, S. B. Lewis, D. Scheutzow, J. Wirz, J. Am. Chem. Soc. 1998, 120, 593; M. Abe, W. Adam, W. T. Borden, M. Hattori, D. A. Hrovat, M. Nojima, K. Nozaki, J. Wirz, J. Am. Chem. Soc. 2004, 126, 574.

[13] P. Haspra, A. Sutter, J. Wirz, Angew. Chem. 1979, 91, 652; Angew. Chem., Int. Ed. 1979, 18, 617.

[14] Y. Chiang, A. J. Kresge, Y. S. Tang, J. Wirz, J. Am. Chem. Soc. 1984, 106, 460.

[15] R. Hochstrasser, J. Wirz, Angew. Chem. 1990, 102, 454; Angew. Chem., Int. Ed. Engl. 1990, 29, 411.

[16] Y. Chiang, A. J. Kresge, R. Hochstrasser, J. Wirz, J. Am. Chem. Soc. 1989, 111, 2355.

[17] M. Capponi, I. Gut, J. Wirz, Angew. Chem. 1986, 98, 358; Angew. Chem., Int. Ed. Engl. 1986, 25, 344. M. Capponi, I. G. Gut, B. Hellrung, G. Persy, J. Wirz, Can. J. Chem. 1999, 77, 605; B. Freiermuth, B. Hellrung, S. Peterli, M.-F. Schultz, D. Wintgens, J. Wirz, Helv. Chim. Acta. 2001, 84, 3976.
[18] J. Wirz, Pure Appl. Chem. 1998, 70, 2221; J. Wirz, Chemie in unserer Zeit 1998, 32, 311.

[19] Y.V. Il'ichev, M. A. Schwörer, J. Wirz, J. Am. Chem. Soc. 2004, 126, 4581.

[20] L. Plistil, T. Solomek, J. Wirz, D. Heger, P. Klan, J. Org. Chem. 2006, 71, 8050.

[21] Y. Kamdzhilov, J. Wirz, Photochem. Photobiol. Sci. 2007, 6, in press.

[22] C. S. Rajesh, R. S. Givens, J. Wirz, J. Am. Chem. Soc. 2000, 122, 611.

[23] H. Boudebous, B. Kosmrlj, B. Sket, J. Wirz, J. Phys. Chem. A 2007, 111, 2811.

[24] P. G. Conrad, R. S. Givens, B. Hellrung, C. S. Rajesh, M. Ramseier, J. Wirz, J. Am. Chem. Soc. 2000, 122, 9346.

[25] J. Wintner, P. Müller, unpublished work.

[26] O. Bieri, J. Wirz, B. Hellrung, M. Schutkowski, M. Drewello, T. Kiefhaber, Proc. Natl. Acad. Sci. 1999, 96, 9597.

[27] S. Canonica, B. Hellrung, J. Wirz, J. Phys. Chem. A 2000, 104, 1226; S. Canonica, T. Kohn, M. Mac, F. J. Real, J. Wirz, U. von Gunten, Environ. Sci. Technol. 2005, 39, 9182; S. Canonica, B. Hellrung, P. Müller, J. Wirz, Environ. Sci. Technol. 2006, 40, 6636.

[28] K. Dietliker, S. Broillet, B. Hellrung, P. Rzadek, G. Rist, J. Wirz, D. Neshchadin, G. Gescheidt, Helv. Chim. Acta 2006, 89, 2211.

[29] R. Born, W. Fischer, D. Heger, B. Tokarczyk, J. Wirz, Photochem. Photobiol. Sci. 2007, 6, 552.

[30] B. Giese, M. Napp, O. Jacques, H. Boudebous, A. M. Taylor, J. Wirz, Angew. Chem., Int. Ed. 2005, 44, 4073.

[31] M. A. Müller, M. Gaplovsky, J. Wirz, W.-D. Woggon, Helv. Chim. Acta 2006, 89, 2987. 